Anuario Latinoamericano Ciencias Políticas

y Relaciones Internacionales

vol. 3, 2016

pp. 89-106

\section{El papel de la Iglesia católica en los conflictos internos latinoamericanos. Diseño de una hipótesis ${ }^{1}$}

\section{The role of the Catholic Church in Latin American internal conflicts. Design of a hypothesis}

\author{
Luis Fernando Pacheco Gutiérrez ${ }^{2}$ \\ UNIVERSIDAD SURCOLOMBIANA, COLOMBIIA \\ $\triangle$ lfernandopacheco@gmail.com
}

\title{
RESUMEN
}

El papel relevante de la Iglesia católica frente a la resolución de conflictos en América Latina en la segunda mitad del siglo XX ha sido innegable. Sin embargo, dicha participación en calidad de mediador o actor de relevancia no se ha comportado como una constante unidireccional. Diversos factores, tales como la relación con la Santa Sede, las influencias ideológicas de movimientos socio-políticos regionales, la relación con el poder local y el nivel de participación en la toma de decisiones, lo han situado en un movimiento pendular entre un férreo compromiso con la paz y la estabilidad de los países latinoamericanos y un desinterés marcado por una no injerencia deliberada en los conflictos internos. La presente propuesta de investigación busca la construcción de una hipótesis sólida a partir del método de análisis comparado en los casos de Argentina, Perú, El Salvador y Colombia.

PALABRAS CLAVES: Latinoamérica, conflictos internos, Iglesia católica, siglo XX.

1 Este artículo es producto de avance de investigación del autor, presentado en la II Conferencia Internacional Latinoamericanista, celebrada los días 3 y 4 de noviembre en la ciudad de Lublin (Polonia) bajo el auspicio de la Universidad Maria Curie-Skłodowska, la Universidad de Varsovia y la Academia Polaca de Ciencias.

2 Docente de tiempo completo de la Universidad Surcolombiana, donde coordina actualmente el área de "América Latina" del Programa de Ciencia Política, carrera de la cual fue Director entre 2012 y 2015. Abogado (Universidad Surcolombiana - Colombia), especialista en Desarrollo Personal y Familiar (Universidad de La Sabana - Colombia), egresado del Curso de Defensa Nacional de la Escuela de Defensa de la República Argentina y candidato a magister en Relaciones Internacionales (Universidad Nacional de La Plata - Argentina). 
América Latina: política y religión

\section{ABSTRACT}

The important role of the Catholic Church in the resolution of conflicts in Latin America in the second half of the twentieth century has been undeniable. However, such participation as mediator or relevant actor has not always been a constant unidirectional way. Various factors, such as the relationship with the Holy See, the ideological influences of regional socio-political movements, the relationship with the local power and the level of participation in decision-making, have placed it in a pendulum movement between an ironclad commitment to peace and stability of Latin American countries and a lack of interest marked by a deliberate noninterference in internal conflicts. This research proposal seeks to build a solid hypothesis from comparative analysis method in the cases of Argentina, Peru, El Salvador and Colombia.

KEYWORDS: Latin America, internal conflicts, Catholic Church, mediation, twentieth century.

\section{Presentación}

El conflicto ha sido un problema recurrente en buena parte de la historia de Latinoamérica, incluso desde antes de llevar dicha denominación, recorriendo su configuración social precolombina, atravesando la llegada de los pueblos colonizadores, pasando por las luchas intestinas de reconfiguración del poder entre las potencias europeas, llegando a los procesos independistas, las consolidaciones republicanas y en mayor medida los tiempos recientes. Sin embargo, dicha conflictividad ha tenido una tendencia a la baja, después de la recuperación democrática que se surtió en la región entre las décadas de los 80 y 90 del siglo pasado, evidenciando una actitud de respeto hacia la democracia y las instituciones, una apertura a la solución pacífica de conflictos y una concepción más activa frente a eventuales escenarios de integración. Dicho proceso de pacificación no ha sido fácil: garantizar la verdad, la justicia y la reparación, acompañado de esfuerzos de las mayorías para tender puentes donde antes hubo divisiones entre facciones sociales, ha sido la estrategia en la mayoría de las naciones latinoamericanas.

Sin embargo, el conflicto armado interno colombiano persiste después de seis décadas como una de las zonas de mayor inestabilidad social en el globo terráqueo y como uno de los obstáculos de desarrollo de la región latinoamericana: de allí la importancia de los diálogos entre las Fuerzas Armadas Revolucionarias (FARC) y el gobierno de Juan Manuel Santos, que se desarrollan desde 2012 con fases escalonadas en Oslo y La Habana. Tras más de tres años de negociación con las FARC, crece la expectativa real de un acuerdo similar entre el Estado colombiano y la guerrilla del ELN, vislumbrando así un probable escenario de firma de acuerdos que faciliten el cumplimiento de los principios de verdad, justicia y reparación. 
Lejos de significar el principio real de la paz, es el comienzo de un camino que requiere la cooperación de diversos actores políticos, y en ello Colombia puede mirar el reflejo de procesos de conflicto y post-conflicto similares, cuya experiencia puede aportar a que esta fase sea más llevadera y eficaz. En este sentido el papel de actores relevantes como los diversos credos religiosos asentados en el país, entre ellos, la Iglesia Católica, una de las instituciones que más ha gozado de repercusión política en Colombia desde tiempos pre-republicanos, pueden ser de suma valía.

Sin embargo, no podemos determinar el rol de la Iglesia en el proceso de post-conflicto sin haber identificado su papel frente a la lucha armada precedente. Lo anterior se muestra como un poderoso condicionante con respecto a qué rol es el que puede llegar a ocupar en la fase ulterior de reconstrucción social.

Los casos de conflicto en Perú (1980-2001), El Salvador (1970-1992), y Argentina (1974-1983) pueden ser casos especialmente interesantes porque, si bien las circunstancias de contexto pueden tener variables diversas, también es cierto que pueden aportar criterios estándares que cooperen al proceso que Colombia ha empezado a construir en búsqueda de su tan anhelada paz.

El presente artículo proviene del diseño de una propuesta de investigación, adelantada por el autor como Director del Grupo de Investigación y Proyección Social "ANDRÉS BELLO" de la Universidad Surcolombiana, para desarrollar en el marco del proceso de paz entre las FARC y el gobierno colombiano. Producto de ello, este escrito es apenas un punto de partida y, en cualquier caso, un diseño de un recorrido investigativo que aporte al saber disciplinar de la ciencia política en Colombia, al papel de diversos actores en las fases venideras del desarrollo social colombiano y que genere una serie de variables, unas categorías de análisis y una hipótesis que sirva como brújula al mencionado proceso.

Estamos convencidos de que ver el caminar de otros, las piedras con que se han tropezado, nos permitirá aprender no cometer los mismos errores y generar aportes pertinentes a la consolidación de paz en la región latinoamericana.

\section{La pertinencia del estudio sobre el papel de actores en el conflicto}

¿Cuál es la pertinencia académica de este estudio? Es necesario que, desde los estudios disciplinares en el campo de la ciencia política, se pueda aportar al momento histórico que vive el país, y aportar elementos a la construcción del proceso de post-conflicto. Colombia atraviesa un momento coyuntural en su construcción socio-política: el proceso de paz que actualmente negocian la guerrilla de las FARC y el gobierno en La Habana es un hecho histórico al margen de su concreción en un acuerdo que lleve a la desmovilización de esta milicia y a la reparación de las víctimas del gobierno armado en Colombia. Como han insistido en afirmarlo representantes de ambos bloques: "nunca antes se había avanzado
El papel de la Iglesia católica en los conflictos internos latinoamericanos. Diseño de una hipótesis

Luis Fernando Pacheco Gutiérrez 
Dossier América Latina: política y religión tanto en materia de paz en este país"(Gobierno Nacional 2013). Aunque el plazo final del 23 de marzo de 2016, que las partes habían establecido como fecha inicial, probablemente no se cumpla por disensos en el contenido final, resulta lógico pensar que, a estas alturas del proceso, nadie quiera levantarse de la mesa y frustrar el avance que han venido sosteniendo las negociaciones.

La importancia de la Iglesia católica en la sociedad es innegable: además de ser un actor de capital importancia en la historia colombiana, al margen de su visión sobre el mundo, eminentemente religiosa, es líder activo en campos importantes del desarrollo como la educación, la salud, la cultura o la reconciliación. Según datos del Anuario Pontificio Estadístico (Santa Sede 2014), más de 10.000 instituciones en el país son administradas o, por lo menos han sido fundadas e impulsadas inicialmente por la Iglesia Católica. Aunque la Constitución Política de 1991 haya establecido un Estado laico, y además, haya propugnado por la separación entre la Iglesia y el Estado, el aporte de las diversas instituciones religiosas resulta ser vital para apoyar tanto social como emocionalmente la reconciliación y (re) construcción de lazos entre los diferentes grupos sociales o comunidades.

Sin embargo, tampoco podemos olvidar que Colombia es un actor importante dentro del marco regional sudamericano. Incluso puede afirmarse que el prolongado conflicto interno que sobrevive más de medio siglo es probablemente el factor de mayor inestabilidad socio-política en la región andina, además de ser, uno de los mayores obstáculos para la proyección del país en el entorno latinoamericano. Por ello, comprender el escenario de un post-conflicto, con todos los retos que esto conlleva y los aportes que se pueden generar en este escenario, resulta vital no solo para las diatribas del país, sino para el futuro de la región.

La importancia histórica de la Iglesia con respecto al conflicto no se ha visto tan sólo en tiempos recientes; de hecho, el involucramiento del clero católico en medio de la división socio-política ha sido un lugar común en la historia latinoamericana. Así lo evidencia Guzmán Carriquiry cuando, analizando el papel del clero católico ante las gestas de independencias de las primeras décadas del siglo XIX, expresa:

(...) las consecuencias de las guerras de emancipación tuvieron grandes costos. El clero estuvo generalmente dividido entre la causa realista y la causa patriótica. Gran parte de los obispos, españoles, peninsulares, escogidos por la monarquía y sujetos al patronato regio sostuvieron la causa realista en América, mientras que algunos otros obispos y muchos sacerdotes y religiosas acompañaron a las huestes revolucionarias. (Carriquiry 2011)

Consideramos que entender el rol de la Iglesia en cada caso concreto conlleva desterrar el mito de la misma como una institución monolítica en su actuar. Encontraremos propuestas, roles e incluso actuaciones divergentes en su interior frente a procesos históricos asimilables. Esta idea se encontrará con 
frecuencia al verificar el comportamiento pos-republicano de la institución y sus relaciones con el Estado.

Como parte fundamental de este texto, procuraré mostrar cómo es que la alternativa de un análisis histórico reciente, que recoja documentos, consideraciones, opiniones, testimonios, experiencias a partir de un método de estudio de análisis comparado, puede ser la alternativa idónea para la problemática propuesta.

\section{El caso comparado como alternativa de estudio}

La historia latinoamericana ha transitado progresivamente por caminos fácilmente asimilables, su colonización, sus procesos de implementación cultural, sus independencias y sus procesos de construcción republicana, pasando por la implementación de un modelo económico, los populismos regionales de mediados del siglo XX, los grupos de izquierda, las dictaduras en el marco de la Doctrina de Seguridad Nacional implementada por Estados Unidos en el marco de la guerra fría para culminar en la recuperación democrática y los primeros contactos para procesos de integración.

En dicho devenir histórico, las historias de los países que conforman Latinoamérica han tenido un destino ligado entre sí y, aunque en ocasiones las diferentes fases no se han vivido de manera paralela cronológicamente hablando, el aprendizaje de múltiples fenómenos a partir de la experiencia de otros países vecinos puede ser útil.

Por lo anterior, consideramos que el método de análisis de estudio comparado puede aportarnos significativamente al margen del periodo histórico en que ocurrieron: la coincidencia de factores y variables en los casos de conflictos latinoamericanos a estudiar genera opciones diversas al proceso de post-conflicto colombiano. A partir de los criterios y reflexiones que ya hemos mencionado abordaremos el estudio comparado de cuatro casos.

\section{El caso de Argentina}

El 1 de julio de 1974, tras el deceso por causas naturales del Presidente Juan Domingo Perón sin completar siquiera su primer año de gobierno, lo sucedió su viuda, María Estela Martínez de Perón (primera mujer en presidir un país latinoamericano), quien fuese su fórmula vicepresidencial. El gobierno de Isabelita - apelativo que usó, incluso más que su nombre de pila - se caracterizó por una inestabilidad política y económica, el fortalecimiento de las guerrillas revolucionarias EPR y Montoneros, y una creciente división al interior de las Fuerzas Armadas con el apelativo ampliamente conocido de ruido de sables. Finalmente, el 24 de marzo de 1976, tras veintiún meses en el poder, la mandataria fue derrocada por un golpe de Estado propinado por las tres fuerzas
El papel de la Iglesia católica en los conflictos internos latinoamericanos. Diseño de una hipótesis

Luis Fernando Pacheco Gutiérrez 
Dossier América Latina: política y religión armadas (Armada, Fuerza Aérea y Ejército), bajo el auto-denominado Proceso de Reorganización Nacional que se sostendría en el poder hasta 1983.

Al respecto, es válido mencionar que, históricamente, son múltiples los autores que distinguen la organización de los actores frente al gobierno de Isabel, con respecto al golpe que terminó con su gobierno y frente a los actos desarrollados por la dictadura durante las cuatro presidencias que se desarrollaron durante la dictadura.

En este sentido, vale la pena destacar las memorias de Julio Carlos González, quien fue Secretario Técnico y Legal de la Presidencia de la Nación durante el tercer gobierno de Perón y el gobierno de su viuda (González 2007), que aporta una visión de testigo presencial de buena parte del proceso de agotamiento y caída del gobierno constitucional, y también sobre el papel que jugaron diversas autoridades y comunidades de la Iglesia en el mismo (por ejemplo, el papel cuestionado de la Nunciatura en Argentina, en cabeza en este periodo, del recientemente fallecido Cardenal italiano Pio Laghi, uno de los diplomáticos más importantes del Colegio Vaticano en el final del siglo XX y principios del siglo XXI, o de Monseñor Tortolo, Capellán castrense designado bajo el gobierno constitucional).

Otro importante análisis es el del fallecido académico argentino Emilio Fermín Mignone (Mignone 1986), quien fue el primer Presidente del Centro de Estudios Legales y Sociales CELS, además de un claro activista en pro de los derechos humanos, quien solo tres años después de la recuperación democrática defendió la tesis de responsabilidad del Episcopado argentino en los desmanes de tortura, desapariciones e implementación de modelos estatales de tortura que desarrolló la dictadura, y su connivencia con las autoridades militares del Proceso. Sin embargo, las versiones apuntan en diversos sentidos, puesto que no solo podemos hablar de una complicidad monolítica en la dictadura, ya que muchos lo identifican como un actor cercano al movimiento revolucionario,especialmente a partir de la relación entre el Movimiento de Sacerdotes del Tercer Mundo, donde imperaba la denominada teología de la liberación y grupos armados de izquierda al margen de la ley, como Montoneros.

Lógicamente, tampoco se podría dejar de considerar el trabajo posterior a la restauración democrática. En este sentido, la Comisión Nacional de Desaparecidos CONADEP, a través del documento conclusivo, denominado "Nunca Más" (Comisión Nacional de Desaparecidos 1984), que rinde informe sobre los excesos del gobierno militar, se convierte en un insumo de especial importancia para determinar participaciones, responsabilidad y roles de la Iglesia durante esta aciaga década.

\section{El caso de El Salvador}

Establecer el principio de la crisis social salvadoreña no resulta una tarea fácil: el conflicto que se desarrolló en el país centroamericano entre los años 70 y 80 entierra sus más profundas raíces en la misma gesta del Estado. Las profundas 
brechas sociales, una economía basada en la agricultura, pero sostenida en un modelo latifundista y terrateniente por excelencia, llevaron a una inestabilidad política traducida en una sucesión de golpes de Estado y represiones sociales.

Sin embargo, en 1970 la constitución del Frente Farabundo Martí para la Liberación Nacional, que nace de la escisión del Partido Comunista, así como las denuncias de fraude en las elecciones presidenciales de 1972 en favor del Coronel Armando Molina -fenómeno que se repetiría cinco años después - fueron la chispa inicial de una guerra civil que trascendió dos décadas, que impactó a la región centroamericana y que se tradujo en más de 75.000 víctimas (entre muertos oficiales y desaparecidos) y sólo cesó con los diálogos de 1992. El caso salvadoreño resulta especialmente emblemático, en virtud de la indudable compenetración de miembros activos de la Iglesia católica dentro de los diferentes bandos de la guerra civil. La misma muerte del Arzobispo de San Salvador, Oscar Arnulfo Romero (recientemente beatificado por el Papa Francisco), el 24 de marzo de 1980, a manos de grupos para-estatales, tras sus continuas denuncias, es aún hoy un símbolo de la violencia que asoló El Salvador y que convirtió a la Iglesia católica en un actor central dentro de dicho proceso.

La Iglesia católica se comprometió ideológicamente - tomando partido en múltiples casos - con la situación conflictual, lo que conllevó un nivel de participación muchísimo más activo en el proceso de reconciliación salvadoreño, donde su participación a través de múltiples iniciativas de reconciliación tuvo mayor protagonismo. En este sentido, vale la pena mencionar el trabajo de la licenciada Hilda Gutiérrez Avelar (Gutiérrez 2007: 13 y ss.) que, si bien a veces parece magnificar el papel altruista, solidario y de espíritu cristiano de la Iglesia (olvidando las dicotomías entre los partidarios de los movimientos sociales y los sectores más afines al gobierno militar), destaca el valor del discurso en la sociedad salvadoreña, que, impregnado de espíritu cristiano e imbuido del mandato evangélico, se transforma en fuerza que es manipulada en el siguiente sentido: (...) el catolicismo se ve influenciado, limitado y orientado por ciertas estrategias de las clases dirigentes, que pretenden incluso la universalización y la sacralización religiosa de las relaciones sociales dominantes. (Gutiérrez 2007: 14)

\section{El caso del Perú}

La situación conflictual del país inca la desarrollaremos a partir de la situación del país entre 1980 y 2001, en torno al conflicto armado que protagonizó el accionar de los grupos revolucionarios Sendero Luminoso y Tupac Amaru, y la respuesta militar del Estado, especialmente, durante el gobierno de Alberto Fujimori en la década de 1990, cuyo impacto repercutió en amplias violaciones a derechos humanos - condenadas en amplia medida por el Sistema Interamericano de Derechos Humanos, y la muerte indiscriminada de víctimas ajenas a los grupos enfrentados.
El papel de la Iglesia católica en los conflictos internos latinoamericanos. Diseño de una hipótesis

Luis Fernando Pacheco Gutiérrez 
Dossier América Latina: política y religión
El caso peruano para efectos de nuestra investigación resulta emblemático, por cuanto en 2001, el Presidente Valentín Paniagua constituyó la Comisión de la Verdad y la Reconciliación, con el objetivo de investigar lo correspondiente a la responsabilidad de las guerrillas Sendero Luminoso y Tupac Amaru y, a su vez, el papel del Estado frente a las violaciones de derechos humanos en su represión a los grupos armados. Dicha Comisión es un precedente importante para nuestra investigación, siendo presidida por Salomón Lerner Febres, Rector de la Pontificia Universidad Católica del Perú PUCP, adquiriendo dicha institución un papel protagónico en la reconstrucción del Posconflicto.

En el caso peruano, contamos con insumos valiosos, puesto que el Informe Final de la Comisión de la Verdad y Reconciliación (Comisión de la Verdad y la Reconciliación - República del Perú 2003) contempla en un acápite especial diversas consideraciones en torno al papel de las Iglesias (católica y otros credos) frente al conflicto interno del país suramericano. Dicho informe constituye punto de partida importante para el sustento de múltiples argumentos en torno al rol que asumieron las organizaciones religiosas (en este caso no solo la católica) durante el conflicto.

Lo anterior no imposibilita un análisis más profundo y no siempre positivo: con amplia experiencia en el tema, podemos mencionar el trabajo de la Profesora Catalina Romero de Iñiguiz, quien, al hacer un análisis ampliado en un artículo del año 1995, no duda en afirmar:

Es frecuente encontrar en los estudios sobre la Iglesia y el Estado, o la Iglesia y la sociedad en general, una hipótesis recurrente que se autocomprueba: (...) la Iglesia (cuyo modelo es la católica) en relación con el Estado u otras instituciones buscan el poder. Poder para controlar las otras esferas del comportamiento humano y de su organización social. (Romero 1995: 382)

Señalados los tres casos emblemáticos que aquí nos propusimos analizar, nos centraremos finalmente en estudiar con una perspectiva histórica el caso colombiano. Como primera medida, debe decirse que nos resulta difícil definir un único conflicto; más ello no es del todo un inconveniente insalvable. De hecho, podemos encontrar intentos de negociación, algunos con frutos indudablemente cuantificables y otros que resultaron fallidos. En este tipo de procesos, la Iglesia ha desempeñado (y sigue haciéndolo) un papel preponderante, sin desconocer los múltiples matices en determinados periodos de tiempo. Vale decir que, en situaciones fácticamente endógenas y exógenas, la Iglesia se ha comprometido activamente a buscar salidas a las tensiones entre el Estado y las organizaciones al margen de la ley.

Aunque a título meramente enunciativo, vale la pena mencionar el rol de la Iglesia en diversos procesos de paz en la historia colombiana, como los diálogos de paz de Caracas y Tlaxcala entre el gobierno colombiano y la guerrilla de las FARC en 1993, el proceso de paz entre la misma guerrilla y el gobierno de Andrés Pastrana Arango en 1993 (estos últimos ambos fallidos), o el papel 
de mediador frente a iniciativas del gobierno de Álvaro Uribe Vélez (como la amnistía al denominado Canciller de las FARC, Rodrigo Granda, que fue acogido como huésped en la sede de la Conferencia Episcopal Colombiana CEC), así como la participación en el proceso de desmovilización de las autodefensas $y$, aunque en menor escala, el papel jugado en la desmovilización del M-19. En el mismo sentido, entre los años 90 y la primera década del siglo actual, la Iglesia Católica ha jugado un rol relevante en la Comisión de Conciliación Nacional, que actualmente es presidida y tiene varios miembros vinculados como clérigos incardinados con prestigio y reconocimiento en el Estado colombiano.

Si bien sería interesante analizar el papel de la Iglesia in extenso, aquí tan sólo nos centraremos en su rol dentro del proceso de diálogo que viene desarrollando desde 2012 el gobierno del Presidente Juan Manuel Santos con la guerrilla de las FARC (primero en Oslo, y luego en La Habana) y que actualmente se encuentran en fase de culminación, con la expectativa de finalizar en el marco del 2016, así como su papel en la eventual negociación con el Ejército de Liberación Nacional ELN.

En la actualidad, para múltiples sectores del Estado y la sociedad civil la reconstrucción del país de cara a un escenario de posconflicto es una realidad, en la que los diversos actores trabajan en la construcción de escenarios de reconciliación y resocialización. Diversas entidades y organizaciones, como, por ejemplo, la Pontificia Universidad Javeriana, organizaron el 7 de diciembre de 2015 en su sede en la capital de la República, un foro con la presencia de académicos y autoridades de la Conferencia Episcopal Colombiana con el fin de determinar derroteros a seguir en aspectos concretos del acuerdo que se está negociando en la capital cubana.

Por ello, consideramos que la alternativa de tomar una serie de casos puntuales y estudiarlos a partir de una metodología comparada que cubra cronológicamente el rol de dicha organización en el marco del surgimiento mismo del conflicto, del devenir del mismo y, lo más importante, en el proceso posterior de reconciliación y construcción de paz, es la alternativa idónea que dentro de un proceso de investigación objetivo y cualificado nos arroje propuestas a la situación actual del caso colombiano.

\section{Variables para diseñar una hipótesis}

Sin bien el presente artículo representa apenas un diseño investigativo que se ha de desarrollar entre 2016 y 2017, la misma estructuración del proyecto conlleva considerar variables previas que pueden haberse desarrollado en mayor o menor medida en cada uno de los casos estudiados.

Ello jamás implicará que no puedan surgir variables adicionales en el mismo desarrollo de la investigación, pero la consideración de una serie de variables previas permitirá una concentración de esfuerzos durante la ejecu-
El papel de la Iglesia católica en los conflictos internos latinoamericanos. Diseño de una hipótesis

Luis Fernando Pacheco Gutiérrez 
Dossier América Latina: política y religión ción del trabajo de campo, durante el desarrollo mismo de la investigación. Dichas variables se han estructurado a partir de una serie de consideraciones, entre las cuales podemos mencionar: en primer lugar, una serie de parámetros jurídico-institucionales que la misma Iglesia católica tiene en su dinámica y que suelen estar estipulados en los documentos que estructuran a la organización (por ejemplo, las disposiciones del Sumo Pontífice, el Código de Derecho Canónico y las constituciones vaticanas) y políticamente a partir de la manera en que se comunica y articula la Iglesia endogámicamente; en segundo lugar, el comportamiento de las diferentes sub-estructuras de la Iglesia católica en el contexto latinoamericano, donde conviven una serie de nuevas realidades político-eclesiales que son marcadamente diferentes de las de otros procesos como, por ejemplo, la Iglesia y la relación con los partidos o los Estados europeos de la Posguerra; y finalmente, una serie de circunstancias propias de relacionamiento como actor en cada uno de los casos de conflicto que hemos tomado como ejemplos en la presente propuesta de investigación, y que pueden marcar resultados diferentes en casos que inicialmente pueden ser asimilables.

En este sentido, hemos podido estructurar cuatro variables previas al proceso de investigación.

\section{La relación con Roma y el nivel de autonomía de las Iglesias locales-nacionales}

El factor jerárquico descentralizado en el cual se articula la Iglesia entre un nivel central representado por el Sumo Pontífice y el Colegio Episcopal en la teoría (pero más bien representada por este con la Curia Vaticana), y un sector descentralizado articulado en diócesis con la titularidad de un Obispo, las cuales, desde la reforma del Concilio Vaticano II, se integran a su vez, en torno a la Conferencia Episcopal de cada país, como un organismo políticopastoral de importante trascendencia. Dicha división en un nivel central y un nivel descentralizado, constituye apenas el principio, al confluir distintos canales de comunicación entre el nivel central y el descentralizado, uno directo y formal entre los Obispos y Roma; uno indirecto y formal establecido a través de las nunciaturas, uno informal y directo entre las diferentes comunidades religiosas que conviven en un país con sus respectivas sedes centrales - y que para efectos de nuestra investigación, puede asumir posturas no necesariamente uniformes frente a las circunstancias de contexto en torno al conflicto - y uno plenamente informal entre las mismas diócesis, arquidiócesis, prelaturas o comunidades religiosas con los diferentes actores del conflicto, que generalmente encarna una postura no formal, lo que conlleva un mayor grado de dificultad en determinar el nivel de involucramiento. En este sentido, tenemos como punto de partida la multiplicidad de factores que jugaron en el caso argentino: la Iglesia no actuó en bloque frente al desarrollo de los sucesos 
que conllevaron el regreso del General Perón en 1973, su asunción a la presidencia, su mandato y el de su viuda y sucesora, y finalmente el golpe militar que derrocó al gobierno constitucional y los hechos que sucedieron hasta el retorno democrático. Podemos incluso mencionar que se optaron por tres vías diversas: una primera que representaba la cooperación de sectores de la Iglesia a la revolución encarnada especialmente por las relaciones entre Montoneros y el movimiento de Sacerdotes para el Tercer Mundo ${ }^{3}$; una segunda, que encarnaba la cooperación formal con las Fuerzas Armadas en el marco del golpe (y que, a su vez, tuvo grupos con distintos matices de cooperación) ${ }^{4}$, y una tercera que decidió actuar en pro de quienes sufrían persecuciones pero desde la clandestinidad. ${ }^{5}$

Este análisis es reiterativo y se puede leer con facilidad en dos textos de vertientes y épocas muy distintas: en primer lugar, el trabajo de Juan Cruz Esquivel (Esquivel 2000), quien sabe distinguir perfectamente las élites eclesiásticas del movimiento de base (que como mencionamos, tuvo comportamientos ambivalentes, tanto durante los gobiernos democráticos de Juan Domingo Perón y de su viuda, como durante la dictadura), acusando especialmente a las primeras de haber cooperado en la práctica con las violaciones sistemáticas de derechos humanos que encabezó la dictadura. En segundo lugar, vale la pena mencionar nuevamente el trabajo del exsecretario, Julio Carlos González, quien en su capítulo "Isabel y el clero" (González 2007: 117 y ss.) respalda la participación de ciertos sectores (no de la institución monolíticamente hablando) en los preludios del golpe de marzo de 1976, y refuerza la idea de

3 El movimiento de Sacerdotes del Tercer Mundo, de especial arraigo en Argentina, se evidenció especialmente en el trabajo de los denominados curas villeros, siendo el caso del P. Mojica, asesinado por la Triple A en 1975 uno de los casos emblemáticos. La cercanía entre sectores eclesiales que abrazaron la teología de la liberación y defendieron lo que se denominó la opción preferente por los pobres no fueron pocos, y se convirtieron en objeto de persecución para las organizaciones paraestatales primero, y más adelante para el Estado, en cabeza de los militares después de marzo de 1976. En cualquier caso y teniendo en cuenta el alcance y el estado actual de la investigación, las presentes referencias no constituyen más que una hipótesis de investigación.

4 En este sentido, se pueden clasificar las menciones hechas a la luz de las memorias de J. C. González, ya reseñadas, donde se señala el papel de complicidad de la Nunciatura apostólica y del Vicariato Castrense y su cooperación con el gobierno sin señalar abiertamente las desapariciones, los ataques y muertes a sacerdotes y obispos por parte de las mismas autoridades del Estado, entre otros.

5 Finalmente, en este sentido - el más difícil de probar evidentemente de los tres - se enmarca una silenciosa acción de autoridades religiosas, cuyo objetivo era determinar objetivos militares del Estado o de los movimientos de guerrillas y utilizar canales diplomáticos para menguar las persecuciones, torturas y desapariciones. En este sentido, se puede mencionar el cuestionado papel del entonces sacerdote, Jorge Mario Bergoglio, Padre Provincial de los Jesuitas en Argentina, y quien se convirtiera, en 1992, en Obispo Vicario y, en 1997, en Arzobispo de Buenos Aires, para finalmente ascender, en marzo de 2014, al trono de San Pedro con el nombre de Francisco. No faltaron entonces los cuestionamientos sobre su papel frente a la dictadura y su silencio, al parecer útil para salvar vidas frente al Proceso de Reorganización Nacional.
El papel de la Iglesia católica en los conflictos internos latinoamericanos. Diseño de una hipótesis

Luis Fernando Pacheco Gutiérrez 
Dossier América Latina: política y religión entender los niveles de participación de Roma en el papel de la iglesia local como dinámicos y sujetos a variables que iban desde el papel de la nunciatura a los múltiples informes desordenados que llegaban a Roma en ese periodo.

\section{La política trazada desde Roma respecto al papel y al nivel de intervención en las iglesias locales-nacionales frente al conflicto}

Si bien la Iglesia católica cuenta con la reputación de ser una institución con niveles mínimos de dinamismo frente a su articulación con las realidades del mundo (siendo ello producto, en mayor o menor medida, de su estructura rígida, su ortodoxia y reticencia a los cambios, y al elevado promedio de duración del gobierno central - representado, claro está por el carácter vitalicio del papado-, dicha sentencia no es irrefutable. De un papado a otro surgen cambios entre la relación de este con las diócesis y comunidades asentadas en los diferentes países latinoamericanos ( $\tan$ lejos de la solemne diplomacia vaticana de los palacios renacentistas romanos) e igualmente dentro de un mismo gobierno de la Iglesia (tanto a nivel central, como en las iglesias locales) ocurren matices importantes: no es lo mismo pensar en la relación de gobierno entre las iglesias latinoamericanas y Juan Pablo II en 1978 o en 1990, que pensarlo en los últimos meses de vida.

Si bien la mayoría de nuestros casos comparados se centran - quizá con excepción del caso colombiano y de la fase final de post-conflicto del caso peruano - durante el papado de Juan Pablo II (1978-2005), tomar dicha política exterior de la Santa Sede como un inamovible durante los 27 años sería indudablemente un error. Consideramos que la percepción romana ${ }^{6}$ del papel que la misma Iglesia debe desempeñar en el conflicto puede variar de una época a otro, situándose entre un movimiento pendular que autorice o motive un papel de mediación más activo versus una idea de mayor neutralidad, que le permita un mayor accionar frente a otras acciones políticas. En este caso, resulta emblemático el trabajo que desarrolló la Universidad Alberto Hurtado de Chile, en su escrito denominado "Historizar el pasado vivo de América Latina” donde Martín Obregón hace un perfecto análisis de dichos roles en su obra (Obregón 2007: 10 a 44), logrando contraponer magistralmente las disputas teológicas que dividieron a América Latina teniendo por telón de fondo en la historia de la Iglesia al periodo post-conciliar bajo el papado de Pablo VI y Juan Pablo II versus el telón político de fondo del ascenso, auge y ocaso de las dictaduras, especialmente de las del cono sur. El trabajo de Obregón nos merece todo el respeto: comprende que no es posible hablar de una sola Iglesia, de una sola interpretación del mandato

6 Utilizamos este término para hacer estricta referencia a la política exterior trazada por el Pontífice desde Roma y ejecutada, generalmente, por la Secretaría de Estado como órgano coordinador y la Nunciatura respectiva como órgano ejecutor. 
que se les ha dado, ni de un solo contexto temporal, sino de las variables que marca cada periodo histórico.

Frente al caso colombiano, y a título meramente indicativo, podemos ver que el nivel del involucramiento de la Iglesia, a partir de las directrices desde Roma, ha sufrido importantes cambios, desde la participación discreta en los procesos de paz de los 80 -cuestionada en algunos casos, por ejemplo, el encuentro entre el entonces Prelado antioqueño y después Cardenal Darío Castrillón Hoyos y el narcotraficante Pablo Escobar Gaviria-, pasando por el tiempo de silencio frente al fracaso de las negociaciones en San Vicente del Caguán entre la guerrilla de las FARC y el gobierno del Presidente Andrés Pastrana Arango entre 1998-2001, hasta el nivel de mediación directo en el que se al mismo Papa Francisco, respecto al actual proceso de negociación que se surte en La Habana entre los mismos actores.

\section{El rol desempeñado como víctima-parte o como agresor-parte}

Hay una tercera variable que consideramos de vital importancia dentro del proyecto de investigación propuesto: la percepción social del grado de involucramiento que la Iglesia haya desempeñado durante el mismo conflicto. En la medida en que la Iglesia católica se vincule en mayor grado a cualquiera de las partes en medio de una confrontación o de una posterior mesa de negociación, además del nivel en que pueda identificarse con el papel de víctima o victimario, más difícil será tener un papel de mediador o conciliador en la fase de conflicto, aunque, paradójicamente, mayor pueda ser su protagonismo y sus aportes en la fase de reconstrucción social posterior al levantamiento de la mesa.

Dentro de esta variable, podremos mencionar dos casos que se pueden enunciar de manera preliminar. En primera medida, con respecto a la identificación con la víctima podemos encontrar el caso salvadoreño: es innegable que la iglesia católica salvadoreña terminó pagando un alto precio por su defensa de determinados sectores ampliamente perseguidos durante los enfrentamientos y bajo la dictadura específicamente, en este sentido se encuentra la misma muerte de Monseñor Romero, Arzobispo Metropolitano de San Salvador en marzo de 1980. Es el trabajo que precisamente defiende la tesis de Gutiérrez Avelar (Gutiérrez 2007: 13 y ss.) al marcar como la Iglesia pasa de ser una conciliadora que cumple con un noble deber (en palabras de la autora), lo que le ocasiona que las élites la conviertan en un objetivo. Dicha tesis es vista desde otro punto de vista por el Rodolfo Cardenal (Cardenal 1995: 156-163), quien sostiene en su artículo del año 1995 que el papel protagónico que tuvo la Iglesia, especialmente encarnada en la Arquidiócesis de San Salvador (de la que fuera titular al momento de su asesinato, Mons. Romero), no se debió a asuntos propiamente ideológicos o al mandato cristiano universal, sino a la capacidad de asimilarse al papel de víctima, lo que le otorgó una credibilidad especial por parte del proceso.
El papel de la Iglesia católica en los conflictos internos latinoamericanos. Diseño de una hipótesis

Luis Fernando Pacheco Gutiérrez 
Dossier América Latina: política y religión
Frente a la segunda posibilidad, la de victimario (o por lo menos cómplice de quien se identifica como tal) encontramos el caso argentino, donde fue fácil ligar el papel de las autoridades eclesiásticas formales (especialmente de la nunciatura o de la vicaría castrense) con la Junta Militar y las principales autoridades de la dictadura.

En la medida en que menos pueda identificarse la institución a cualquiera de los dos roles (por demás inexactos, pero clásicos en cualquier proceso de negociación, dividir los buenos y los malos o, por lo menos, las conductas enmarcadas dentro del derecho internacional de las que no lo son, por ejemplo) más difícil le es encarnar un nivel de legitimidad en el proceso de negociación. Paradójicamente, este rol, que puede ser percibido por la sociedad, no lo deslegitima en el proceso del post-conflicto.

Por el contrario, las experiencias de los casos salvadoreño y argentino (especialmente el primero) no deslegitimaron la acción de la Iglesia en el proceso posterior, antes bien, le concedieron autoridad para adelantar iniciativas de reconciliación. Ello tiene una directa relación con la coordinación de ambas fases: mientras que la primera está bajo la batuta de los grupos enfrentados, bajo la discreta coordinación de quienes ejercen como mediadores, en la fase de post-conflicto son los diversos actores políticos de la sociedad civil quienes protagonizan y lideran iniciativas que pacifiquen y busquen reconciliar a partir de los principios de verdad, justicia y reparación. La calidad de involucramiento en el conflicto parece reforzar la autoridad para participar en el proceso, e indudablemente, a ello se suma la legitimidad que su histórico prestigio social le brinda, así como su presencia en buena parte de los respectivos territorios nacionales.

\section{El rol dentro del proceso de negociación}

Muy ligada a la variable anterior es la que indica cuál ha sido el rol de la institución durante la fase de negociación, ya que la distancia o el nivel de participación en los acuerdos mínimos a los que se llegan pueden marcar una tendencia importante sobre el nivel de participación en las fases posteriores.

Para efectos de nuestra propuesta de investigación, el caso emblemático para considerar esta variable es Perú, donde el papel que jugó la Iglesia, la Conferencia Episcopal del país inca, la Pontificia Universidad Católica de este país y personajes públicamente identificados como católicos, le valió un especial reconocimiento que permite mayor protagonismo, con las consecuencias positivas o negativas que ello puede implicar y que desarrollaremos en mayor detalle dentro del proyecto de investigación.

Este enfoque que podemos denominar propositivo posterior, puesto que le otorga a la Iglesia (junto a otras confesiones arraigadas en los casos colombiano y centroamericanos en general) predomina en el documento de trabajo del Centro de Estudios Americanos \& Latinos de American University 
(Fuentes 2013: 1-32). Si bien dicha visión no pretende ser una absolución per se respecto al papel de la Iglesia en los mencionados conflictos, tampoco puede desconocerse que tras levantarse "exitosamente" de un proceso de negociación externo, las alternativas plausibles para paliar las heridas físicas y psicológicas requieres acciones concretas, en lo posible de actores con experiencia en la materia.

El mencionado trabajo del CLALS tiene además un valor adicional que resulta innegable: no sólo enumera una serie de iniciativas, sino que, a partir del trabajo de talleres que articula el relato, aborda preguntas fundamentales que son necesarias para comprender los motivos y estrategias de la Iglesia para actuar. Un claro ejemplo de esta labor es el desarrollo de la pregunta ¿Qué motiva a las iglesias a actuar? (Fuentes 2013: 10-14).

\section{Consideraciones finales}

La presente investigación es una propuesta por el autor suscrito como Director del Grupo de Investigación y Proyección Social "ANDRÉS BELLO" dentro de la Convocatoria para financiar proyectos de Investigación de Mediana Cuantía, proferida por la Vicerrectoría de Investigaciones y Proyección Social de la Universidad Surcolombiana (Colombia) para ejecutarse entre los meses de agosto de 2016 y julio de 2017, a partir de la hipótesis, variables, factores y metodología, presentados en el presente artículo y a partir de investigaciones primarias desarrolladas al interior de la mencionada universidad estatal colombiana.

En cuanto a la metodología, vale mencionar que estamos frente a una investigación cualitativa de método de análisis comparado a partir de los casos mencionados, que se estructurará en tres fases que incluyen: una recolección bibliográfica amplia, académica y periodística que genere un mapa previo del rol de la institución en el contexto tempo-espacial de cada uno de los conflictos; y dos fases más que implican un trabajo de campo propiamente hablando, estructurado a partir de documentos, en lo posible fuentes directas que nos indiquen el papel que representó en cada una de las fases de los conflictos en estudio, para culminar con testimonios de protagonistas directos que puedan aportarnos una visión de construcción de memoria que podamos contrarrestar con el material recogido en las fases 1 y 2 del proyecto.

Es menester mencionar que, comprometidos con la paz latinoamericana, pero desde una visión que sea respaldada por la ciencia, la objetividad y la verdad, sin hacer apología de una investigación panfletaria o comprometida con una ideología o una causa, esperamos que los resultados de esta propuesta de investigación no se agoten en una publicación, sino en una propuesta de experiencias que coopere a la paz, no solo colombiana, sino en general de la región latinoamericana. Los resultados de dicha investigación serán difundidos en publicaciones académicas de reconocimiento, pudiendo ser una de ellas, la presente publicación en ediciones futuras.
El papel de la Iglesia católica en los conflictos internos latinoamericanos. Diseño de una hipótesis

Luis Fernando Pacheco Gutiérrez 
Dossier América Latina: política y religión

\section{Conclusiones}

A partir de lo anterior, podemos extraer las siguientes conclusiones.

Para la ciencia política, resulta especialmente importante y valioso el estudio del papel de los diferentes actores políticos con relevancia dentro de la sociedad, frente a procesos de conflictividad y la superación de los mismos. Entender el rol que juegan y pueden jugar dichos actores favorece el desarrollo de estrategias sólidas de institucionalización. Con base en lo dicho, el papel de la Iglesia católica, por su prestigio social, por su peso histórico y por el contexto de cada una de las situaciones nacionales latinoamericanas, es un caso emblemático para el análisis.

Adicional a ello, hay una pertinencia social en el contexto histórico actual latinoamericano y es el caso colombiano: desde 2012 se viene desarrollando con escenarios en Oslo y La Habana una serie de diálogos entre la guerrilla de las FARC y el gobierno colombiano. Se espera que en los próximos meses se inicien similares acciones de negociación con la guerrilla del ELN, poniendo fin a una etapa de más de medio siglo de violencia, muerte y atraso, siendo uno de los conflictos más arraigados en el contexto latinoamericano.

Considerando lo anterior, y frente al diseño de la presente propuesta hemos optado por método de investigación a partir de la técnica de estudio de casos comparados, permitiendo que, al ser asimilables múltiples procesos históricos de los países latinoamericanos, la experiencia de otros procesos de conflicto y pacificación generen insumos, elementos al análisis y propuestas para el caso actual: en ese sentido, se estudiarán los conflictos de Argentina (1974-1983), El Salvador (1970-1992), Perú (1980-2001) y, lógicamente, el caso colombiano, haciendo especial referencia a los procesos de negociación fallidos de los 90, el de 1998-2001, y, como lo habíamos mencionado, las respectivas referencias al proceso actual con las FARC.

Existen una serie de variables a considerar que pueden influir de manera determinante en las particularidades que cada caso presenta. Dichas variables generan un innegable aporte al método investigativo. A título meramente indicativo, y sin cerrar la puerta a que puedan aparecer más durante el mismo desarrollo de la investigación, podemos mencionar las siguientes: (i) la articulación entre la Santa Sede y los diferentes estamentos eclesiales locales, como diócesis, comunidades religiosas o nunciaturas; (ii) la política exterior trazada desde Roma en directa relación con cada uno de los conflictos y los periodos en estudio, entendida como una realidad dinámica y adaptada a variables menores; (iii) la percepción de identificación con el rol de víctima o victimario, lo cual podría conllevar una pérdida de legitimidad en el mismo proceso de negociación; o (iv) el grado de mediación que la institución - en este caso, lógicamente, la Iglesia - tenga en el proceso de negociación, lo cual otorgaría legitimidad para un mayor protagonismo en la fase siguiente, la del post-acuerdo.

El presente artículo refleja los parámetros teóricos sobre los cuales se ha desarrollado una propuesta de investigación a ejecutarse en el periodo comprendido entre agosto de 2016 y julio de 2017. Consideramos, sin embargo, 
especialmente importante construir una propuesta argumentada desde lo científico, para darle mayor relevancia a los aportes teóricos y prácticos que los resultados de dicha propuesta pueden tener frente a situaciones concretas, como el fortalecimiento de los estudios en la línea de religión y política en América Latina, pero además como un aporte real de insumos al caso colombiano en su actual proceso de paz.

\section{Bibliografía}

Cardenal R. (1995), Iglesia y proceso de paz: el caso de El Salvador, "Nueva Sociedad", no 136, pp. 156-163.

Carriquiry Lecour G. (2011), El bicentenario de la independencia de los países latinoamericanos, Editorial Encuentro, Madrid.

Comisión de la Verdad y la Reconciliación- República del Perú (2003), Informe Final, Lima, disponible en: http://www.cverdad.org.pe/ifinal/index.php, fecha de consulta: 20.10.2015.

Comisión Nacional de Desaparecidos, CONADEP (1984), Nunca Más, Buenos Aires, disponible en: http://www.desaparecidos.org/nuncamas/web/investig/articulo/nuncamas/ nmas0001.htm, fecha de consulta: 21.10.2015.

Donado García W. E. (2013), El papel de la Iglesia en el pos-conflicto, Miqueas Global 6, Lima, pp. 1-13, disponible en: http://www.micahnetwork.org/sites/default/files/doc/page/ el_papel_de_la_iglesia_en_el_postconflicto_donado_3.pdf, fecha de consulta:: 11.02.2013.

Esquivel J. C. (2000), Iglesia católica, política y sociedad: un estudio de las relaciones entre la élite eclesiástica argentina, el Estado y la sociedad en perspectiva histórica, en: publicación informe final del concurso: Democracia, derechos sociales y equidad; y Estado, Política y conflictos sociales. Programa Regional de Becas CLACSO, Buenos Aires, disponible en: http://biblioteca. clacso.edu.ar/clacso/becas/20110112035544/esquivel.pdf, fecha de consulta: 31.01.2016.

Fuentes Dary C. (2013), Las Iglesias ante las violencias en Latinoamérica. Modelos y experiencias de paz en contextos de conflicto y violencia, en: CLALS Working Paper Series, no 3, Center for Latin American and Latino Studies, Washington, pp. 1-32, disponible en: http://www.american.edu/clals/upload/CLALS-Working-Paper_Iglesia-y-violencia.pdf, fecha de consulta: 22.02.1016.

Gobierno Nacional, República de Colombia (2013), Alocución presidencial, Bogotá, 20 de diciembre.

González J. C. (2007), Isabel Perón: intimidades de un gobierno, Editorial El Ateneo, Buenos Aires.

Gutiérrez Avelar H. G. (2007), El papel de la Iglesia católica en la guerra civil salvadoreña reflejada en las homilías y cartas pastorales de Monseñor Oscar Arnulfo Romero y su reflejo en testimonios de guerra del municipio Las Vueltas (Chalatenango), monografía para optar por el título de Licenciada en Letras, Universidad de El Salvador, San Salvador.

Márquez Fariñas J. M. (2011), La Iglesia católica de cara a los cambios en América Latina, "Revista de la Biblioteca Nacional José Martî", no 2, La Habana, pp. 80-97.

Mignone E. F. (1986), Iglesia y dictadura: la experiencia argentina, "Nueva Sociedad", no 82, Buenos Aires, pp. 121-128.

Obregón M. (2007), La Iglesia argentina durante la última dictadura militar. El terror desplegado sobre el campo católico (1976-1983), en: Historizar el pasado vivo en América Latina, A. Pérotin-
El papel de la Iglesia católica en los conflictos internos latinoamericanos. Diseño de una hipótesis

Luis Fernando Pacheco Gutiérrez 
Dossier América Latina: política y religión
Dumon ed., Universidad Alberto Hurtado, Santiago de Chile, disponible en: http://etica. uahurtado.cl/historizarelpasadovivo/es_contenido.php, fecha de consulta: 31.01.2016.

Romero C. (1995), Iglesia y sociedad en el Perú: mirando hacia el siglo XXI, en: El Perú frente al siglo XXI, Fondo Editorial de la Pontificia Universidad Católica del Perú, Lima, disponible en: http://files.pucp.edu.pe/departamento/economia/LDE-1995-01-15.pdf, fecha de consulta: 21.11.2016.

Santa Sede, Secretaría de Estado (2014), Anuario Pontificio Estadístico, Roma.

Siglas

CEC

ELN

Conferencia Episcopal Colombiana

Ejercito de Liberación Nacional

Ejército Revolucionario del Pueblo

FARC Fuerzas Armadas Revolucionarias de Colombia

FMLN Frente Farabundo Martí para la Liberación Nacional

PUCP Pontificia Universidad Católica del Perú 